Article

\title{
A 1,6-Diphenylpyrene-Based, Photoluminescent Cyclophane Showing a Nematic Liquid-Crystalline Phase at Room Temperature
}

\author{
Yoshimitsu Sagara ${ }^{1,2, * \mathbb{C}}$, Tatsuya Muramatsu ${ }^{1}$ and Nobuyuki Tamaoki ${ }^{1}$ \\ 1 Research Institute for Electronic Science, Hokkaido University, N20, W10, Kita-Ku, Sapporo, \\ Hokkaido 001-0020, Japan; mtatsu@eis.hokudai.ac.jp (T.M.); tamaoki@es.hokudai.ac.jp (N.T.) \\ 2 JST-PRESTO, Honcho 4-1-8, Kawaguchi, Saitama 332-0012, Japan \\ * Correspondence: sagara@es.hokudai.ac.jp
}

Received: 21 January 2019; Accepted: 9 February 2019; Published: 11 February 2019

check for updates

\begin{abstract}
Photoluminescent nematic liquid crystals have been an attractive research target for decades, because of their potential applications in optoelectrical devices. Integration of luminescent motifs into cyclic structures is a promising approach to induce low-ordered liquid-crystalline phases, even though relatively large and rigid luminophores are used as emitters. Here, we demonstrate a 1,6-diphenylpyrene-based, unsymmetric cyclophane showing a stable nematic phase at room temperature and exhibiting strong photoluminescence from the condensed state. The observed sky-blue photoluminescence was dominated by the emission species ascribed to assembled luminophores rather than monomers.
\end{abstract}

Keywords: liquid crystal; photoluminescence; pyrene; fluorescence; cyclophane

\section{Introduction}

Photoluminescent liquid crystals have attracted much attention because of their potential applications in displays, polarized light-emitting materials, and stimuli-responsive luminescent materials [1-6]. Nematic liquid-crystalline (LC) phases are preferable for such purposes, because the homogeneous/homeotropic alignment of molecules can be easily achieved [7,8]. In nematic phases, molecules have long-range orientational order and have no positional order [7,8]. However, it is still challenging to modify the molecular structure of $\pi$-extended luminophores so that they show nematic LC phases at room temperature (r.t.). Relatively large and rigid $\pi$-conjugated moieties lead to strong intermolecular interactions, like the $\pi-\pi$ interaction, resulting in a strong tendency to form more ordered LC phases, such as smectic, columnar, and cubic phases [2,9-12].

Since a series of cyclic main-chain oligomers were found to show nematic LC behavior in 1992 [13], the LC properties of various cyclic compounds have been investigated. For example, Percec and co-workers demonstrated that cyclic oligomers exhibit LC phases over a wider temperature range compared with the linear analogues [14-17]. Tschierske's and Hegmann's groups have reported LC behavior of low-molecular-weight cyclophanes [18-21]. Though various mesogens were used in the cyclic LC compounds, highly luminescent $\pi$-conjugated groups have not been used as mesogens so far.

The course of our previous studies on luminescent cyclophanes [22-29] suggested that the introduction of a cyclic structure into luminophores is a promising way to achieve mechanoresponsive luminescent materials [3,4,30-36]. Luminescent cyclophanes having longer spacers have been found to show nematic LC properties. Especially, unsymmetric cyclophanes, which have only one luminophore exhibiting photoluminescence in the visible wavelength region in the cyclic structure, show a nematic phase in a lower temperature range in comparison with the symmetric analogues containing 
two luminophores in an individual cycle [23-25]. Furthermore, the unsymmetric cyclophanes exhibit kinetically trapped LC phases with nematic molecular order after rapid cooling from the nematic state. As the phases with nematic order are thermodynamically metastable, moderate thermal treatment easily induces phase transitions to stable crystalline phases. The transitions are concomitant with photoluminescence color changes. However, highly luminescent cyclophanes showing thermodynamically stable nematic phases at r.t. have not been prepared yet.

Here, we report a 1,6-diphenylpyrene-based, unsymmetric cyclophane that exhibits a stable nematic LC phase at r.t. The cyclic compound shows strong blue and sky-blue photoluminescence in solution and LC phases, respectively.

\section{Materials and Methods}

\subsection{General Method}

All reagents and solvents were purchased from Fujifilm Wako and Tokyo Kasei. Unless otherwise noted, all reactions were carried out under a nitrogen atmosphere. Flash silica gel column chromatography was carried out with a Biotage Isolera flash system using Biotage Flash Cartridges or SHOKO-scientific Purif-Pack-EX cartridges. Silica gel from Kanto Chemicals (silica gel 60 N, spherical, 63-210 $\mu \mathrm{m}$ ) was used when flash silica gel column chromatography was conducted in a conventional manner. Recycling preparative gel permeation chromatography (GPC) was performed with a Japan Analytical Industry LaboACE. ${ }^{1} \mathrm{H}$ NMR spectra were recorded on a JEOL JNM-ECX 400 spectrometer, and all chemical shifts are quoted on the $\delta$-scale in ppm relative to the signal of tetramethylsilane (at 0.00 ) as an internal standard. ${ }^{13} \mathrm{C}$ NMR spectra were recorded on a JEOL JNM-ECX 400 spectrometer, and all chemical shifts $(\delta)$ are reported in ppm using residual solvents as the internal standard $\left(\mathrm{CDCl}_{3}\right.$ at 77.16, DMSO- $\mathrm{d}_{6}$ at 39.52). Coupling constants $(J)$ are reported in $\mathrm{Hz}$ and relative intensities are also shown. Matrix-assisted laser desorption ionization time-of-flight (MALDI-TOF) mass spectra were obtained on an AB SCIEX TOF/TOF 5800. The differential scanning calorimetry (DSC) measurements were conducted using Hitachi DSC7020 with a heating/cooling rate of $5^{\circ} \mathrm{C} / \mathrm{min}$ under a nitrogen atmosphere. XRD measurements were carried out with a Rigaku SmartLab. UV-vis absorption spectra were measured with a JASCO V-550. Steady-state fluorescence spectra were recorded on a JASCO FP-6500. Time-resolved fluorescence measurements were carried out with a Hamamatsu Photonics Quantaurus-Tau. Quantum efficiencies were measured with a Hamamatsu Photonics Quantaurus-QY. Polarized optical microscopic observations were conducted with an Olympus BX-60 optical microscope equipped with a Shimadzu Moticam 1080.

\subsection{Synthesis}

The synthetic routes used to prepare cyclophane $\mathbf{1}$ and compound $\mathbf{2}$ are shown in Scheme 1; Scheme 2, respectively. 1,5-Bis(2-[2-(2-\{2-[2-(2-bromoethoxy)ethoxy]ethoxy\}ethoxy) ethoxy]ethoxy)naphthalene and 2-(2-(2-methoxyethoxy)ethoxy)ethyl 4-methylbenzenesulfonate were synthesized according to reported procedures [25,37]. 

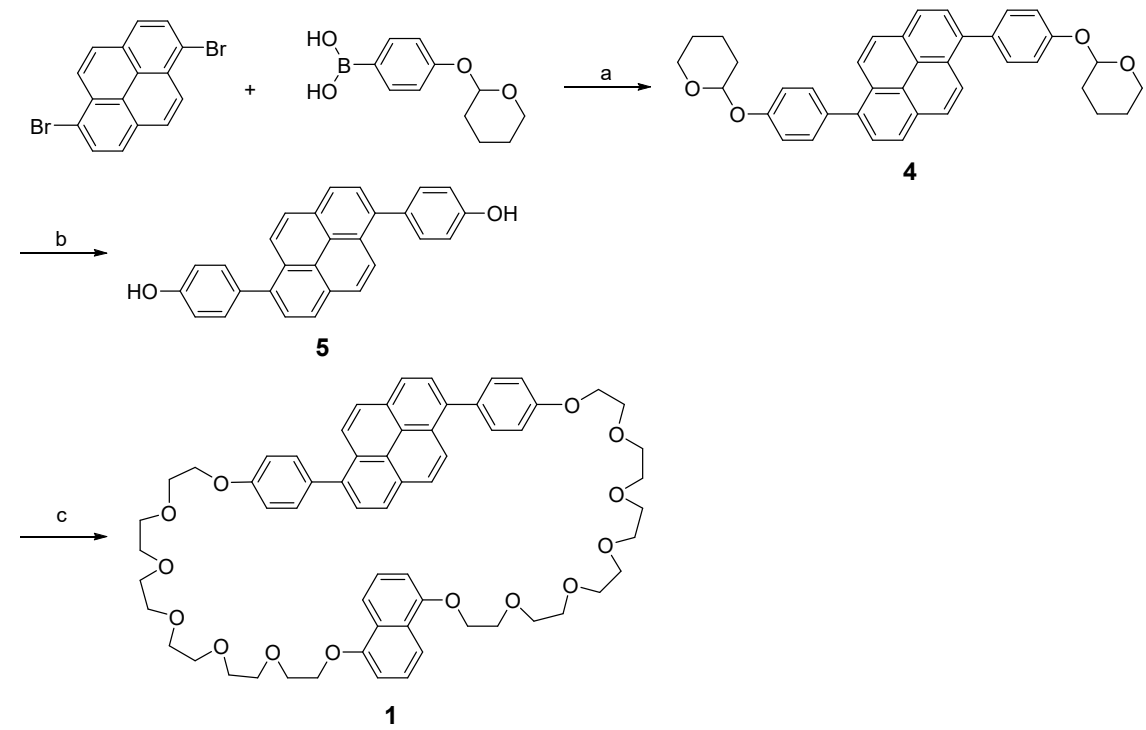

Scheme 1. Synthesis of cyclophane 1. Conditions: (a) $\mathrm{Pd}\left(\mathrm{PPh}_{3}\right)_{4}, \mathrm{~K}_{2} \mathrm{CO}_{3}$, toluene, $\mathrm{H}_{2} \mathrm{O}$, reflux, $15 \mathrm{~h}$; (b) $10 \%$ aq. $\mathrm{HCl}, \mathrm{CHCl}_{3}, 70{ }^{\circ} \mathrm{C}, 3 \mathrm{~h}$; (c) 1,5-bis(2-[2-(2-\{2-[2-(2-bromoethoxy)ethoxy]ethoxy\}ethoxy)-ethoxy] ethoxy)naphthalene, $\mathrm{K}_{2} \mathrm{CO}_{3}, \mathrm{DMF}, 80{ }^{\circ} \mathrm{C}, 24 \mathrm{~h}$.

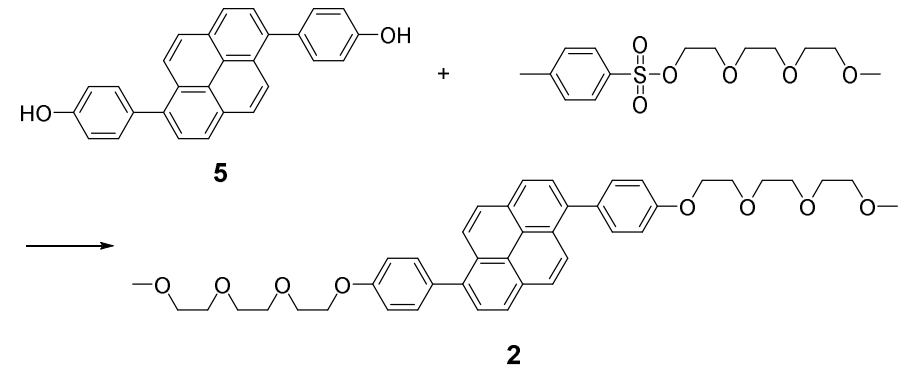

Scheme 2. Synthesis of compound 2. Conditions: $\mathrm{K}_{2} \mathrm{CO}_{3}, \mathrm{DMF}, 80^{\circ} \mathrm{C}, 15 \mathrm{~h}$.

Compound 4. A mixture of 1,6-dibromopyrene (500 mg, $1.39 \mathrm{mmol})$, 4-tetrahydro- $2 \mathrm{H}$ -pyran-2-yloxy)phenylboronic acid (615 mg, $2.77 \mathrm{mmol}), \mathrm{Pd}\left(\mathrm{PPh}_{3}\right)_{4}\left(80.0 \mathrm{mg}, 6.92 \times 10^{-2} \mathrm{mmol}\right)$, and $\mathrm{K}_{2} \mathrm{CO}_{3}(763 \mathrm{mg}, 5.52 \mathrm{mmol})$ in toluene $(40 \mathrm{~mL})$ and $\mathrm{H}_{2} \mathrm{O}(5 \mathrm{~mL})$ was degassed and heated to reflux for $15 \mathrm{~h}$. After cooling to r.t., the reaction suspension was poured into chloroform $(200 \mathrm{~mL})$. The organic layer was washed with saturated aq. $\mathrm{NaCl}$ solution $(2 \times 100 \mathrm{~mL})$, dried over $\mathrm{MgSO}_{4}$, and filtered, after which the solvent was evaporated. The crude product was purified by flash column chromatography on silica gel (eluent: hexane/chloroform $=1: 5$ ) and subsequently precipitated from a mixture of chloroform and hexane to afford compound $4(635 \mathrm{mg}, 1.14 \mathrm{mmol})$ as yellow solid with a yield of $82 \% .{ }^{1} \mathrm{H}$ NMR $\left(400 \mathrm{MHz}, \mathrm{CDCl}_{3}\right): \delta=1.64-1.79(\mathrm{~m}, 6 \mathrm{H}), 1.93-1.97(\mathrm{~m}, 4 \mathrm{H}), 2.04-2.13(\mathrm{~m}, 2 \mathrm{H})$, 3.67-3.73 (m, 2H), 4.00-4.06 (m, 2H), $5.57(\mathrm{t}, J=3.2 \mathrm{~Hz}, 2 \mathrm{H}), 7.25(\mathrm{~d}, J=8.8 \mathrm{~Hz}, 4 \mathrm{H}), 7.56(\mathrm{~d}, J=8.8 \mathrm{~Hz}$, $4 \mathrm{H}), 7.96(\mathrm{~d}, J=8.0 \mathrm{~Hz}, 2 \mathrm{H}), 8.02(\mathrm{~d}, J=9.2 \mathrm{~Hz}, 2 \mathrm{H}), 8.17(\mathrm{~d}, J=8.0 \mathrm{~Hz}, 2 \mathrm{H}), 8.21(\mathrm{~d}, J=9.2 \mathrm{~Hz}, 2 \mathrm{H})$. ${ }^{13} \mathrm{C}$ NMR $\left(100 \mathrm{MHz}, \mathrm{CDCl}_{3}\right): \delta=19.03,25.41,30.60,62.37,96.63,116.46,124.51,125.41,127.46,127.95$, 129.06, 130.36, 131.75, 134.68, 137.63, 156.61. MS (MALDI-TOF): m/z: 554.28 (calcd. [M] $\left.{ }^{+}=554.24\right)$.

Compound 5. A mixture of $4(940 \mathrm{mg}, 1.69 \mathrm{mmol}), 10 \%$ aq. $\mathrm{HCl}(5 \mathrm{~mL})$ solution, and chloroform $(200 \mathrm{~mL})$ was heated to reflux for $3 \mathrm{~h}$ and subsequently cooled to room temperature. Water $(20 \mathrm{~mL})$ was added, most of the chloroform was evaporated, and the solid product was filtered off. The solid was washed with water $(2 \times 20 \mathrm{~mL})$ and methanol $(2 \times 5 \mathrm{~mL})$. The product was dried in vacuo to afford compound $5(577 \mathrm{mg}, 1.49 \mathrm{mmol})$ as a yellow solid with a yield of $88 \%$. ${ }^{1} \mathrm{H}$ NMR $(400 \mathrm{MHz}$, DMSO- $\left.\mathrm{d}_{6}\right): \delta=7.01(\mathrm{~d}, J=8.4 \mathrm{~Hz}, 4 \mathrm{H}), 7.45(\mathrm{~d}, J=8.4 \mathrm{~Hz}, 4 \mathrm{H}), 7.98(\mathrm{~d}, J=7.6 \mathrm{~Hz}, 2 \mathrm{H}), 8.13-8.18(\mathrm{~m}$, $4 \mathrm{H}), 8.29(\mathrm{~d}, J=8 \mathrm{~Hz}, 2 \mathrm{H}), 9.72(\mathrm{br}, 2 \mathrm{H}) .{ }^{13} \mathrm{C}$ NMR $\left(100 \mathrm{MHz}, \mathrm{DMSO}-\mathrm{d}_{6}\right): \delta=115.50,124.63,124.65$, 
127.43, 127.89, 128.11, 129.54, 130.97, 131.49, 137.44, 157.03. MS (MALDI-TOF): m/z: 386.19 (calcd. [M] ${ }^{+}$ $=386.13$ ).

Cyclophane 1. Compound 5 (300 mg, $0.776 \mathrm{mmol})$ and 1,5-bis(2-[2-(2- $\{2-[2-(2-$ bromoethoxy) ethoxy] ethoxy\}ethoxy)ethoxy]ethoxy)naphthalene $(632 \mathrm{mg}, 0.776 \mathrm{mmol})$ in DMF (50 mL) was dropwise added to a suspension of $\mathrm{K}_{2} \mathrm{CO}_{3}(1.07 \mathrm{~g}, 7.74 \mathrm{mmol})$ in $\mathrm{DMF}(300 \mathrm{~mL})$ at $80^{\circ} \mathrm{C}$ over $4 \mathrm{~h}$ under vigorous stirring. After further stirring for $20 \mathrm{~h}$ at $80^{\circ} \mathrm{C}$, the solvent was evaporated. Ethyl acetate $(100 \mathrm{~mL})$ was added and the organic layer was washed with saturated aq. $\mathrm{NH}_{4} \mathrm{Cl}$ solution $(3 \times 300 \mathrm{~mL})$ and saturated aq. $\mathrm{NaCl}$ solution $(100 \mathrm{~mL})$. The organic layer was dried over $\mathrm{MgSO}_{4}$ and filtered, and the solvent was evaporated. The crude product thus isolated was purified by flash column chromatography on silica gel (eluent: dichloromethane/acetone $=85: 15$ ) and recycling GPC (eluent: chloroform) to afford cyclophane 1 (280 mg, $0.269 \mathrm{mmol})$ as a pale yellow viscous liquid with a yield of $35 \% .{ }^{1} \mathrm{H} \mathrm{NMR}$ $\left(400 \mathrm{MHz}, \mathrm{CDCl}_{3}\right): \delta=3.58-3.68(\mathrm{~m}, 20 \mathrm{H}), 3.70-3.80(\mathrm{~m}, 16 \mathrm{H}), 3.94-3.98(\mathrm{~m}, 8 \mathrm{H}), 4.28-4.30(\mathrm{~m}, 4 \mathrm{H})$, $6.48(\mathrm{~d}, J=7.6 \mathrm{~Hz}, 2 \mathrm{H}), 7.07(\mathrm{t}, J=8.0 \mathrm{~Hz}, 2 \mathrm{H}), 7.13(\mathrm{~d}, J=8.8 \mathrm{~Hz}, 4 \mathrm{H}), 7.52(\mathrm{~d}, J=8.8 \mathrm{~Hz}, 4 \mathrm{H}), 7.67(\mathrm{~d}, J$ $=8.8 \mathrm{~Hz}, 2 \mathrm{H}), 7.89(\mathrm{~d}, J=7.6 \mathrm{~Hz}, 2 \mathrm{H}), 7.94(\mathrm{~d}, J=9.2 \mathrm{~Hz}, 2 \mathrm{H}), 8.06(\mathrm{~d}, J=8.0 \mathrm{~Hz}, 2 \mathrm{H}), 8.15(\mathrm{~d}, J=9.2 \mathrm{~Hz}$, 2H). ${ }^{13} \mathrm{C} \mathrm{NMR}\left(100 \mathrm{MHz}, \mathrm{CDCl}_{3}\right): \delta=67.37,67.67,69.51,69.66,70.39,70.45,70.51,70.62,70.63,70.65$, $70.88,105.15,114.27,114.67,124.36,124.81,124.99,125.10,126.36,127.29,127.67,128.68,130.00,131.49$, 133.55, 137.24, 153.96, 158.15. HRMS (ESI): $\mathrm{m} / \mathrm{z}: 1061.4680$ (calcd. $\left.[\mathrm{M}+\mathrm{Na}]^{+}=1061.4663\right)$.

Compound 2. A suspension of compound 5 (150 mg, $0.388 \mathrm{mmol}), 2-(2-(2-$ methoxyethoxy) ethoxy)ethyl 4-methylbenzenesulfonate $(247 \mathrm{mg}, 0.776 \mathrm{mmol})$ and $\mathrm{K}_{2} \mathrm{CO}_{3}(160 \mathrm{mg}, 1.16 \mathrm{mmol})$ in DMF $(100 \mathrm{~mL})$ was stirred for $15 \mathrm{~h}$ at $80^{\circ} \mathrm{C}$. After cooling to room temperature, the solvent was evaporated. Chloroform was added, and the organic layer was washed with saturated aq. $\mathrm{NH}_{4} \mathrm{Cl}$ solution $(3 \times$ $300 \mathrm{~mL}$ ) and saturated aq. $\mathrm{NaCl}$ solution $(100 \mathrm{~mL})$. The organic layer was dried over $\mathrm{MgSO}_{4}$ and filtered, and the solvent was evaporated. The crude product thus isolated was purified by flash column chromatography on silica gel (eluent: dichloromethane $/$ acetone $=20: 1$ to dichloromethane $/$ acetone $=$ 10:1) to afford compound $2(85.0 \mathrm{mg}, 0.125 \mathrm{mmol})$ as a pale yellow solid with a yield of $32 \% .{ }^{1} \mathrm{H}$ NMR $\left(400 \mathrm{MHz}, \mathrm{CDCl}_{3}\right): \delta=3.38(\mathrm{~s}, 6 \mathrm{H}), 3.55-3.57(\mathrm{~m}, 4 \mathrm{H}), 3.66-3.72(\mathrm{~m}, 8 \mathrm{H}), 3.76-3.79(\mathrm{~m}, 4 \mathrm{H}), 3.90-3.92$ $(\mathrm{m}, 4 \mathrm{H}), 4.21-4.23(\mathrm{~m}, 4 \mathrm{H}), 7.09(\mathrm{~d}, J=8.8 \mathrm{~Hz}, 4 \mathrm{H}), 7.53(\mathrm{~d}, J=8.8 \mathrm{~Hz}, 4 \mathrm{H}), 7.93(\mathrm{~d}, J=8.0 \mathrm{~Hz}, 2 \mathrm{H}), 8.00$ $(\mathrm{d}, J=9.6 \mathrm{~Hz}, 2 \mathrm{H}), 8.15(\mathrm{~d}, J=8.0 \mathrm{~Hz}, 2 \mathrm{H}), 8.18(\mathrm{~d}, J=9.2 \mathrm{~Hz}, 2 \mathrm{H}) .{ }^{13} \mathrm{C}$ NMR $\left(100 \mathrm{MHz}, \mathrm{CDCl}_{3}\right): \delta=$ $58.92,67.45,69.68,70.49,70.58,70.76,71.85,114.44,124.33,125.07,125.17,127.27,127.73,128.79,130.10$, 131.50, 133.62, 137.35, 158.14. HRMS (ESI): m/z: 701.3087 (calcd. $\left.[\mathrm{M}+\mathrm{Na}]^{+}=701.3090\right)$.

\section{Results and Discussion}

\subsection{Molecular Designs}

1,6-Diphenylpyrene-based, unsymmetric cyclophane $\mathbf{1}$ and the linear analogue 2 are shown in Schemes 1 and 2. 1,6-Disubstituted pyrene derivatives are known to show emissions with high quantum yields [25,38-40]. Cyclophane 3 (Figure 1) was previously investigated in the course of our studies on luminescent cyclophanes [25]. The thermodynamically stable state of $\mathbf{3}$ at r.t. is a crystalline phase, though kinetic trapping can induce a supercooled nematic phase at r.t. Relatively large, planar 1,6-bis(phenylethynyl)pyrene moiety permits cyclophane 3 to form a closed-packed molecular arrangement. Therefore, 1,6-diphenylpyrene was used as the luminescent core of $\mathbf{1}$, because steric hindrance between protons of the pyrene group and adjacent phenyl groups would disturb the closed-packed arrangement of the luminescent groups. As in the case of 3, 1,5-disubstituted naphthalene featuring hexaethylene glycol chains was introduced to achieve the cyclic structure of $\mathbf{1}$. 


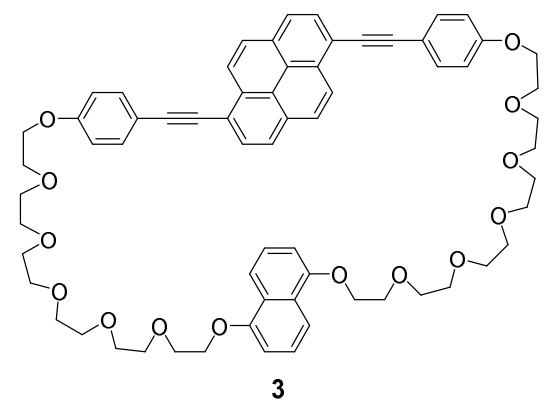

Figure 1. Molecular structure of cyclophane 3.

\subsection{LC Properties}

As expected, cyclophane 1 shows a nematic LC phase at r.t. and exhibits sky-blue photoluminescence under excitation light of $365 \mathrm{~nm}$. The characteristic schlieren texture of a nematic phase appears on the polarized optical microscopic observation at r.t. (Figure 2). DSC measurements clarified the phase transition behavior of cyclophane 1 (Figure 3). A phase transition from isotropic to nematic was observed at $57.6^{\circ} \mathrm{C}$ on cooling, and further cooling results in a glass transition at $-15.1^{\circ} \mathrm{C}$. In contrast with unsymmetric cyclophanes investigated in our previous studies [23-25], no transitions to crystalline phases appear on the heating DSC traces. As shown in Figure 4, no clear peaks were observed in the X-ray diffraction pattern obtained from cyclophane $\mathbf{1}$ at r.t., which coincides with the fact that cyclophane 1 exhibits the nematic LC phase at r.t. In contrast to 1 with a cyclic structure, acyclic compound 2 shows a transition to a crystalline phase at $80^{\circ} \mathrm{C}$, and no LC phases appear on cooling (Figure S1, in the Supplementary Materials). In the case of compound 3, the nematic-crystalline phase transition was observed at $67.4^{\circ} \mathrm{C}$ on the cooling DSC trace [25]. These results unambiguously indicated that the unsymmetric cyclic structure is vital for inducing low-ordered liquid crystallinity. Furthermore, the non-planar character of the luminophore of $\mathbf{1}$ that results from steric hindrance between protons of the pyrene and phenyl groups would prevent crystallization.

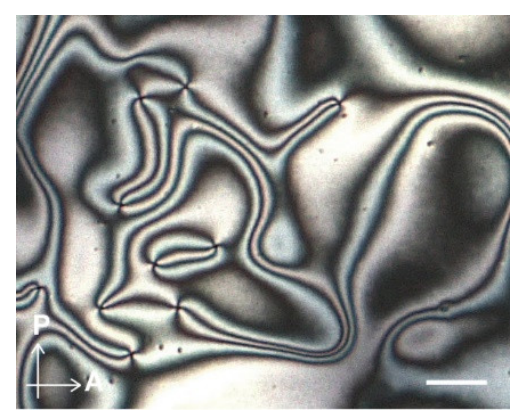

Figure 2. Polarized optical microscopic image of pyrene-based cyclophane $\mathbf{1}$ at r.t. in the absence of a coverslip. Scale bar: $20 \mu \mathrm{m}$. 


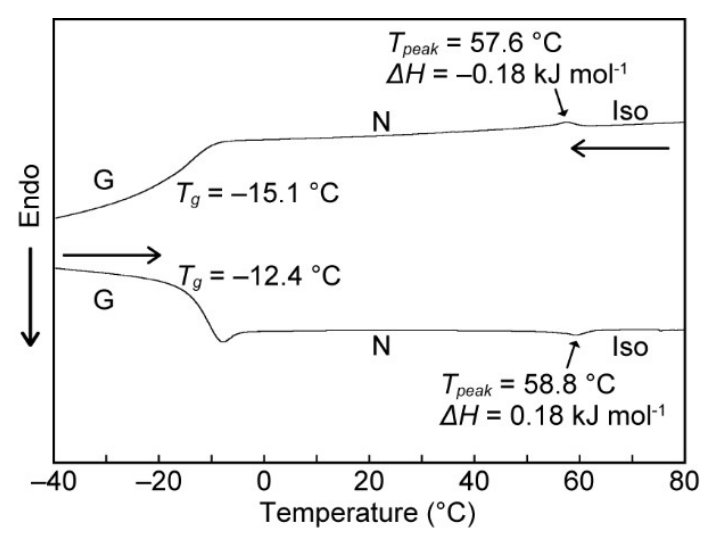

Figure 3. DSC traces of cyclophane 1 on heating and cooling. $T_{\text {peak }}$ : transition temperature taken at the top point of the transition peaks; $T_{g}$ : grass transition temperature; $\Delta H$ : transition enthalpy. G: glassy; $\mathrm{N}$ : nematic; Iso: isotropic. Scanning rate was $5{ }^{\circ} \mathrm{C} \mathrm{min}^{-1}$.

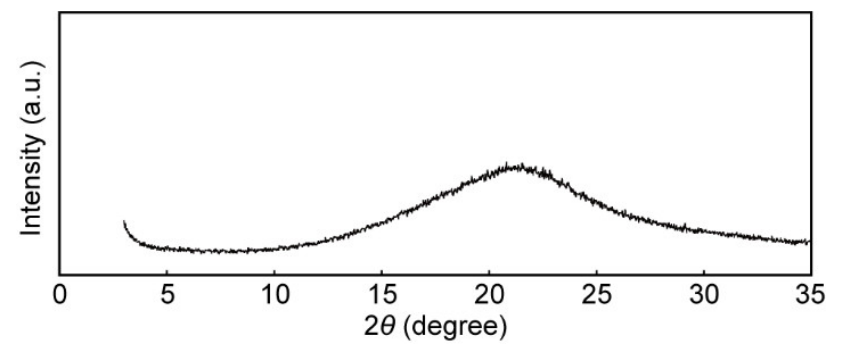

Figure 4. X-ray diffractogram of cyclophane $\mathbf{1}$ in the nematic phase at r.t.

\subsection{Absorption and Photoluminescence Properties}

Absorption and photoluminescence spectroscopic measurements were performed to obtain photophysical properties of compounds $\mathbf{1}$ and $\mathbf{2}$ in solution (Figure 5). The linear compound $\mathbf{2}$ displays the absorption band corresponding to a 1,6-diphenylpyrene group between 300 and $400 \mathrm{~nm}$, with a molar extinction coefficient of $3.8 \times 10^{4} \mathrm{~L} \mathrm{~mol}^{-1} \mathrm{~cm}^{-1}$ at $360 \mathrm{~nm}$ (Figure 5a, black line). The absorption band of $\mathbf{1}$ in chloroform shows a slight red-shift in comparison with that of the chloroform solution of $\mathbf{2}$, suggesting that feeble ground state electronic interactions between the pyrene and naphthalene moieties occur in solution (Figure 5a, blue line). The increase in the absorption between 280 and $330 \mathrm{~nm}$ is attributed to the naphthalene group of $\mathbf{1}$. Compound $\mathbf{2}$ in chloroform displays the emission spectrum with a peak at $409 \mathrm{~nm}$ and shoulders around 430 and $470 \mathrm{~nm}$ (Figure 5b, black line). The emission spectrum recorded for the chloroform solution of $\mathbf{1}$ is almost identical to that of the chloroform solution of $\mathbf{2}$, implying that the photoluminescence from cyclophane $\mathbf{1}$ is a monomer emission. This is supported by the emission lifetime measurements for chloroform solutions of $\mathbf{1}$ and 2 . As shown in Figure 6, the emission decay profile of $\mathbf{1}$ in chloroform is identical to that of the chloroform solution of 2 . Both profiles can be fitted with a single exponential decay function, and the calculated emission lifetimes of $\mathbf{1}$ and $\mathbf{2}$ in chloroform are 1.9 and $1.8 \mathrm{~ns}$, respectively. The fluorescence quantum yield of $\mathbf{1}$ in chloroform $(\Phi=0.68)$ is also similar to that of compound $\mathbf{2}$ in the same solvent $(\Phi=0.67)$. 
(a)

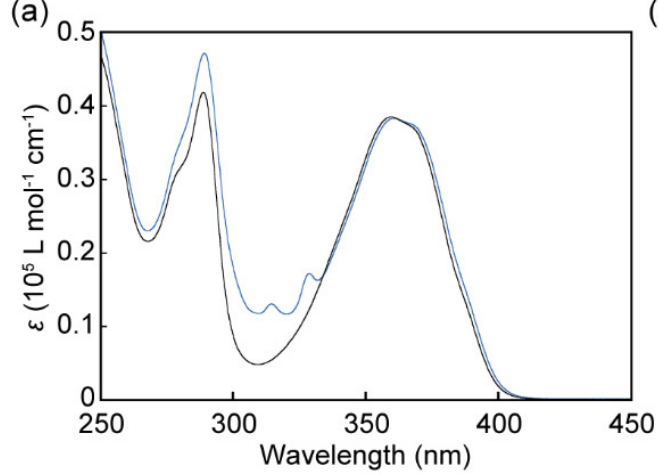

(b)

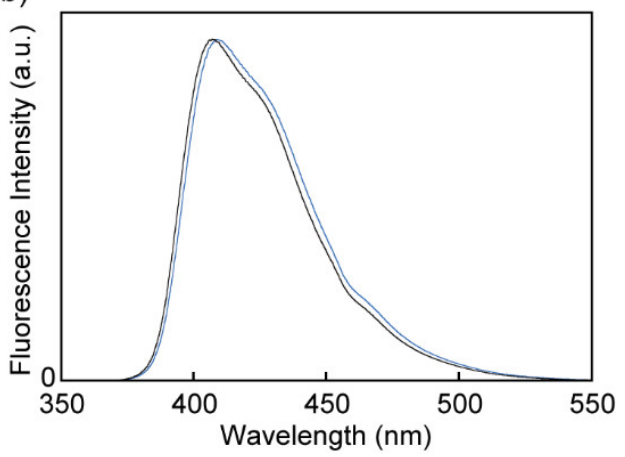

Figure 5. (a) Absorption and (b) fluorescence spectra of compounds 1 (blue line) and 2 (black line) in chloroform $\left(\mathrm{c}=1.0 \times 10^{-5} \mathrm{M}\right)$. The emission spectra were obtained with excitation light of $350 \mathrm{~nm}$.

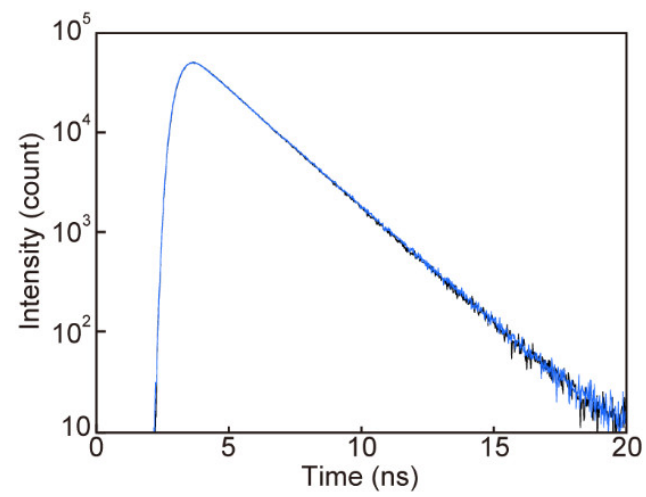

Figure 6. Emission decay profiles of the chloroform solution of $\mathbf{1}$ (blue line) and $\mathbf{2}$ (black line). The profiles were monitored at $410 \mathrm{~nm}\left(\lambda_{\mathrm{ex}}=365 \mathrm{~nm}\right)$.

\subsection{Photoluminescence Properties of $\mathbf{1}$ in the Nematic Phase}

Photoluminescence properties of $\mathbf{1}$ in the nematic phase were also investigated. The emission spectrum presents peaks at 452 and $469 \mathrm{~nm}$ and has a shoulder around $500 \mathrm{~nm}$ (Figure 7). The emission spectral feature is significantly different from that of the chloroform solution of $\mathbf{1}$ (Figure $5 \mathrm{~b}$ ), indicating that emission species other than a monomer dominate the former emission character. This is supported by the fact that the emission decay profile recorded for the nematic phase could be fitted with a multi-exponential decay function (Figure 8). A longer emission lifetime of $23 \mathrm{~ns}$, as well as shorter ones (1.0, 3.1, and $8.0 \mathrm{~ns})$ were obtained. The newly observed emission lifetimes would be ascribed to assembled luminophores, because the luminophore of cyclophane $\mathbf{1}$ can form various arrangements in the nematic phase, reflecting low-ordered LC properties. Indeed, the absorption band between 350 and $400 \mathrm{~nm}$ of cyclophane 1 in the nematic phase was red-shifted and broadened compared with that of the chloroform solution of $\mathbf{1}$ (Figure S2). This result indicated that ground state electronic interactions occur between adjacent luminophores in the condensed states. It is noteworthy that cyclophane 1 shows a relatively high emission quantum yield of 0.51 in the nematic phase at r.t. 


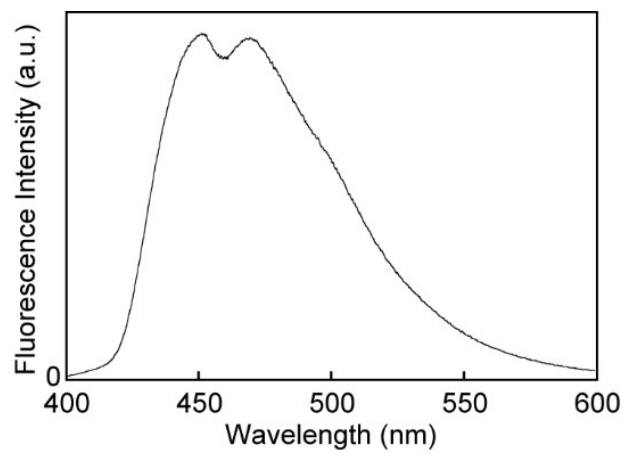

Figure 7. Fluorescence spectrum of cyclophane 1 in the nematic phase at r.t. $\left(\lambda_{\mathrm{ex}}=350 \mathrm{~nm}\right)$.

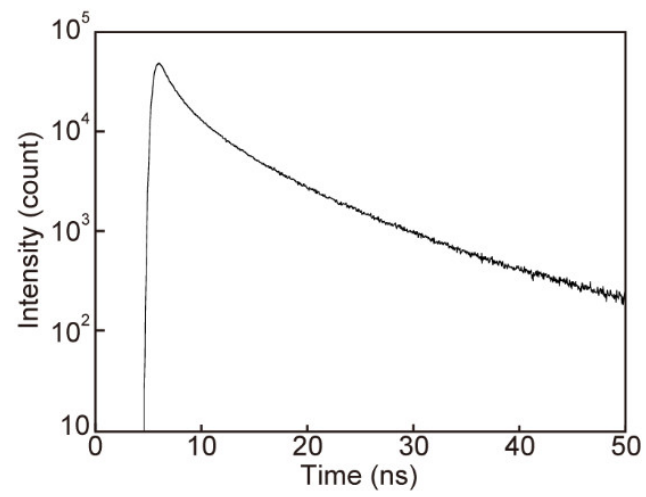

Figure 8. Emission decay profile of $\mathbf{1}$ in the nematic phase at r.t. The profile was monitored at $450 \mathrm{~nm}$ $\left(\lambda_{\mathrm{ex}}=365 \mathrm{~nm}\right)$.

\section{Conclusions}

In summary, a new unsymmetric cyclophane having a 1,6-diphenylpyrene group was found to show a nematic phase at r.t. Cyclophane 1 shows strong blue photoluminescence ascribed to the monomer emission in chloroform, whereas the emissions from the nematic phase are composed of various emission species that result from luminophore assemblies. The present result indicated that the introduction of a cyclic structure into luminophores that are known to exhibit high photoluminescence quantum yields is a reliable way to achieve a nematic LC phase at r.t. Because nematic liquid crystals with high emission quantum efficiencies have potential applications in sophisticated optoelectronic devices, development of other luminophores with a cyclic structure is ongoing in our group.

Supplementary Materials: The following are available online at http:/ / www.mdpi.com/2073-4352/9/2/92/s1, Figure S1: DSC trace of compound 2, Figure S2: absorption spectrum of $\mathbf{1}$ in the nematic phase.

Author Contributions: Conceptualization, Y.S.; methodology, Y.S.; synthesis of compounds and characterization, Y.S. and T.M.; writing—original draft preparation, Y.S. and T.M.; writing—review and editing, Y.S., T.M. and N.T.

Funding: This research was funded by the Japan Society for the Promotion of Science, Kakenhi grant number JP18H02024.

Acknowledgments: We thank Y. Urano for emission quantum yield measurements. We also thank Miho Yamada for HRMS measurements.

Conflicts of Interest: The authors declare no conflict of interest.

\section{References}

1. Kato, T.; Uchida, J.; Ichikawa, T.; Sakamoto, T. Functional liquid crystals towards the next generation of materials. Angew. Chem. Int. Ed. 2018, 57, 4355-4371. [CrossRef] 
2. Wang, Y.; Shi, J.; Chen, J.; Zhu, W.; Baranoff, E. Recent progress in luminescent liquid crystal materials: Design, properties and application for linearly polarised emission. J. Mater. Chem. C 2015, 3, 7993-8005. [CrossRef]

3. Sagara, Y.; Kato, T. Mechanically induced luminescence changes in molecular assemblies. Nat. Chem. 2009, 1, 605-610. [CrossRef]

4. Sagara, Y.; Yamane, S.; Mitani, M.; Weder, C.; Kato, T. Mechanoresponsive Luminescent Molecular Assemblies: An Emerging Class of Materials. Adv. Mater. 2016, 28, 1073-1095. [CrossRef]

5. Yamane, S.; Tanabe, K.; Sagara, Y.; Kato, T. Stimuli-responsive photoluminescent liquid crystals. Top. Curr. Chem. 2012, 318, 395-405.

6. Rosen, B.M.; Wilson, C.J.; Wilson, D.A.; Peterca, M.; Imam, M.R.; Percec, V. Dendron-Mediated Self-Assembly, Disassembly, and Self-Organization of Complex Systems. Chem. Rev. 2009, 109, 6275-6540. [CrossRef]

7. Goodby, J.W.; Collings, P.J.; Kato, T.; Tschierske, C.; Gleeson, H.; Raynes, P.; Vill, V. Handbook of Liquid Crystals, 2nd ed.; Goodby, J.W., Collings, P.J., Kato, T., Tschierske, C., Gleeson, H., Raynes, P., Vill, V., Eds.; WileyVCH: Weinheim, Germany, 2014.

8. Singh, G.; Vijaya Prakash, G.; Choudhary, A.; Biradar, A.M. Homeotropic alignment of nematic liquid crystals with negative dielectric anisotropy. Phys. B Condens. Matter 2010, 405, 2118-2121. [CrossRef]

9. Kato, T.; Yasuda, T.; Kamikawa, Y.; Yoshio, M. Self-assembly of functional columnar liquid crystals. Chem. Commun. 2009, 0, 729-739. [CrossRef]

10. Funahashi, M. Nanostructured liquid-crystalline semiconductors-A new approach to soft matter electronics. J. Mater. Chem. C 2014, 2, 7451-7459. [CrossRef]

11. Wu, J.; Pisula, W.; Müllen, K. Graphenes as potential material for electronics. Chem. Rev. 2007, 107, 718-747. [CrossRef]

12. O’Neill, M.; Kelly, S.M. Ordered materials for organic electronics and photonics. Adv. Mater. 2011, 23, 566-584. [CrossRef] [PubMed]

13. Percec, V.; Kawasumi, M.; Rinaldi, P.L.; Litman, V.E. Synthesis and characterization of cyclic liquid crystalline oligomers based on 1-(4-hydroxy-4'-biphenylyl)-2-(4-hydroxyphenyl)butane and 1,10-dibromodecane. Macromolecules 1992, 25, 3851-3861. [CrossRef]

14. Percec, V.; Turkaly, P.J.; Asandei, A.D. Macrocyclization Overrides the Polymer Effect in the Stabilization of Liquid Crystalline (LC) Phases with a Novel Odd-Even Alternation. A Demonstration with LC Crown Ethers. Macromolecules 1997, 30, 943-952. [CrossRef]

15. Percec, V.; Asandei, A.D.; Ungar, G. From Regioirregular Linear Main-Chain Liquid-Crystal Polyethers Exhibiting Two Uniaxial Nematic Phases to Macrocyclic Main-Chain Oligoethers Displaying Nematic and Smectic Phases. Chem. Mater. 1996, 8, 1550-1557. [CrossRef]

16. Percec, V.; Asandei, A.D.; Chu, P. Design of Side Chain and Main Chain Liquid Crystalline Polymers Containing Supramolecular Quasi-Rigid-Rodlike Mesogens Obtained from Collapsed Main Chain Macrocyclics. Macromolecules 1996, 29, 3736-3750. [CrossRef]

17. Percec, V.; Kawasumi, M. Liquid-crystalline polyethers based on conformational isomerism. 32. Effect of molecular weight on the phase behavior of linear and macrocyclic oligoethers and of linear polyethers based on 1-(4-hydroxy-4'-biphenylyl)-2-(4-hydroxyphenyl)butane and 1,10-dibromodecane. Macromolecules 1993, $26,3663-3675$.

18. Hegmann, T.; Neumann, B.; Wolf, R.; Tschierske, C. Liquid crystalline paracyclophanes and ansa compounds-series of polyether macrocycles incorporating diacetylene, phenyl, biphenyl, p-terphenyl and 2,5-diphenyl-1,3,4-thiadiazole rigid cores. J. Mater. Chem. 2005, 15, 1025-1034. [CrossRef]

19. Neumann, B.; Hegmann, T.; Wagner, C.; Ashton, P.R.; Wolf, R.; Tschierske, C. Liquid crystalline macrocycles containing phenylpyrimidine units. J. Mater. Chem. 2003, 13, 778-784. [CrossRef]

20. Neumann, B.; Hegmann, T.; Wolf, R.; Tschierske, C. Binuclear cyclopalladated cyclophanes: Towards a new family of metallomesogens. Chem. Commun. 1998, 105-106. [CrossRef]

21. Neumann, B.; Joachimi, D.; Tschierske, C. Liquid crystalline macrocycles: Novel glass-forming nematic materials that can undergo charge transfer induced phase transitions. Adv. Mater. 1997, 9, 241-244. [CrossRef]

22. Sagara, Y.; Tamaoki, N.; Fukuhara, G. Cyclophane-Based Fluorescence Tuning Induced by Hydrostatic Pressure Changes. ChemPhotoChem 2018, 2, 959-963. [CrossRef] 
23. Sagara, Y.; Seki, A.; Kim, Y.; Tamaoki, N. Linearly polarized photoluminescence from an asymmetric cyclophane showing thermo- and mechanoresponsive luminescence. J. Mater. Chem. C 2018, 6, 8453-8459. [CrossRef]

24. Mase, K.; Sasaki, Y.; Sagara, Y.; Tamaoki, N.; Weder, C.; Yanai, N.; Kimizuka, N. Stimuli-Responsive Dual-Color Photon Upconversion: A Singlet-to-Triplet Absorption Sensitizer in a Soft Luminescent Cyclophane. Angew. Chem. Int. Ed. 2018, 57, 2806-2810. [CrossRef] [PubMed]

25. Sagara, Y.; Weder, C.; Tamaoki, N. Asymmetric Cyclophanes Permit Access to Supercooled Nematic Liquid Crystals with Stimulus-Responsive Luminescence. Chem. Mater. 2017, 29, 6145-6152. [CrossRef]

26. Sagara, Y.; Tamaoki, N. Mechanoresponsive luminescence and liquid-crystalline behaviour of a cyclophane featuring two 1,6-bis(phenylethynyl)pyrene groups. RSC Adv. 2017, 7, 47056-47062. [CrossRef]

27. Sagara, Y.; Weder, C.; Tamaoki, N. Tuning the thermo- and mechanoresponsive behavior of luminescent cyclophanes. RSC Adv. 2016, 6, 80408-80414. [CrossRef]

28. Sagara, Y.; Simon, Y.C.; Tamaoki, N.; Weder, C. A mechano- and thermoresponsive luminescent cyclophane. Chem. Commun. 2016, 52, 5694-5697. [CrossRef] [PubMed]

29. Sagara, Y.; Karman, M.; Verde-Sesto, E.; Matsuo, K.; Kim, Y.; Tamaoki, N.; Weder, C. Rotaxanes as Mechanochromic Fluorescent Force Transducers in Polymers. J. Am. Chem. Soc. 2018, 140, 1584-1587. [CrossRef] [PubMed]

30. Calvino, C.; Sagara, Y.; Buclin, V.; Haehnel, A.P.; del Prado, A.; Aeby, C.; Simon, Y.C.; Schrettl, S.; Weder, C. Mechanoresponsive, Luminescent Polymer Blends Based on an Excimer-Forming Telechelic Macromolecule. Macromol. Rapid Commun. 2018, 40, 1800705. [CrossRef] [PubMed]

31. Haehnel, A.P.; Sagara, Y.; Simon, Y.C.; Weder, C. Mechanochemistry in Polymers with Supramolecular Mechanophores. Top. Curr. Chem. 2015, 369, 345-375.

32. Sagara, Y.; Mutai, T.; Yoshikawa, I.; Araki, K. Material Design for Piezochromic Luminescence: Hydrogen-Bond-Directed Assemblies of a Pyrene Derivative. J. Am. Chem. Soc. 2007, 129, 1520-1521. [CrossRef] [PubMed]

33. Ma, Z.; Wang, Z.; Teng, M.; Xu, Z.; Jia, X. Mechanically Induced Multicolor Change of Luminescent Materials. Chemphyschem 2015, 16, 1811-1828. [CrossRef]

34. Zhang, X.; Chi, Z.; Zhang, Y.; Liu, S.; Xu, J. Recent advances in mechanochromic luminescent metal complexes. J. Mater. Chem. C 2013, 1, 3376-3390. [CrossRef]

35. Chi, Z.; Zhang, X.; Xu, B.; Zhou, X.; Ma, C.; Zhang, Y.; Liu, S.; Xu, J. Recent advances in organic mechanofluorochromic materials. Chem. Soc. Rev. 2012, 41, 3878-3896. [CrossRef] [PubMed]

36. Balch, A.L. Dynamic crystals: Visually detected mechanochemical changes in the luminescence of gold and other transition-metal complexes. Angew. Chem. Int. Ed. 2009, 48, 2641-2644. [CrossRef] [PubMed]

37. Yoshimoto, M.; Honda, K.; Kurosawa, S.; Tanaka, M. Dynamic Properties of Self-Assembled Monolayers of Mercapto Oligo(ethylene oxide) Methyl Ether on an Oscillating Solid-Liquid Interface. J. Phys. Chem. C 2014, 118, 16067-16073. [CrossRef]

38. Suneesh, C.V.; Gopidas, K.R. Long-Lived Photoinduced Charge Separation Due to the Inverted Region Effect in 1,6-Bis(phenylethynyl)pyrene-Phenothiazine Dyad. J. Phys. Chem. C 2010, 114, 18725-18734. [CrossRef]

39. Sagara, Y.; Komatsu, T.; Ueno, T.; Hanaoka, K.; Kato, T.; Nagano, T. Covalent attachment of mechanoresponsive luminescent micelles to glasses and polymers in aqueous conditions. J. Am. Chem. Soc. 2014, 136, 4273-4280. [CrossRef] [PubMed]

40. Maeda, H.; Maeda, T.; Mizuno, K.; Fujimoto, K.; Shimizu, H.; Inouye, M. Alkynylpyrenes as Improved Pyrene-Based Biomolecular Probes with the Advantages of High Fluorescence Quantum Yields and Long Absorption/Emission Wavelengths. Chem. Eur. J. 2006, 12, 824-831. [CrossRef] [PubMed]

(C) 2019 by the authors. Licensee MDPI, Basel, Switzerland. This article is an open access article distributed under the terms and conditions of the Creative Commons Attribution (CC BY) license (http:/ / creativecommons.org/licenses/by/4.0/). 